\title{
Brown adipose tissue: is it affected by intermittent hypoxia?
}

\author{
Denis Martinez ${ }^{1}$, Cintia Z Fiori2 ${ }^{2}$, Diego Baronio ${ }^{3}$, Alicia Carissimi ${ }^{3}$, Renata SR Kaminski ${ }^{3}$, Lenise J Kim, \\ Darlan P Rosa ${ }^{3}$, Ângelo Bos ${ }^{5}$
}

\begin{abstract}
Background: Intermittent hypoxia $(I H)$, a model of sleep apnea, produces weight loss in animals. We hypothesized that changes in brown adipose tissue (BAT) function are involved in such phenomenon. We investigated the effect of $\mathrm{H}$, during 35 days, on body weight, brown adipose tissue wet weight (BATww) and total protein concentration (TPC) of BAT.
\end{abstract}

Methods: We exposed Balb/c mice to 35 days of $\mathrm{IH}(n=12)$ or sham intermittent hypoxia $(\mathrm{SIH} ; \mathrm{n}=12)$, alternating 30 seconds of progressive hypoxia to a nadir of 6\%, followed by 30 seconds of normoxia. During 8 hours, the rodents underwent a total of 480 cycles of hypoxia/reoxygenation, equivalent to an apnea index of 60/hour. BAT was dissected and weighed while wet. Protein was measured using the Lowry protein assay.

Results: Body weight was significantly reduced in animals exposed to $\mathrm{H}$, at day 35 , from $24.4 \pm 3.3$ to $20.2 \pm 2.2 \mathrm{~g}$ $(p=0.0004)$, while in the SIH group it increased from $23.3 \pm 3.81$ to $24.1 \pm 2.96 \mathrm{~g}(p=0.23)$. BATww was also lower in $\mathrm{IH}$ than in SIH group ( $p=0.00003)$. TPC of BAT, however, was similar in $1 \mathrm{H}(204.4 \pm 44.3 \mu \mathrm{g} / 100 \mu \mathrm{L})$ and $\mathrm{SIH}$ groups $(213.2 \pm 78.7 \mu \mathrm{g} / 100 \mu \mathrm{L} ; \mathrm{P}=0.74)$ and correlated neither with body weight nor with BATww. TPC appeared to be unaffected by exposure to $\mathrm{H}$ also in multivariate analysis, adjusting for body weight and BATww. The correlation between body weight and BATww is significant ( $r h o=0.63)$ for the whole sample. When $\mathbb{H}$ and SIH groups are tested separately, the correlations are no longer significant (rho $=0.48$ and 0.05 , respectively).

Conclusion: $\mathrm{IH}$ during 35 days in a mice model of sleep apnea causes weight loss, BATww reduction, and no change in TPC of BATww. The mechanisms of weight loss under IH demands further investigation.

\section{Background}

Obstructive sleep apnea (OSA) [1,2], is characterized by recurrent episodes of partial or total pharyngeal obstruction [3] during sleep, leading to asphyxia. The clinical consequences of OSA emerge from the intermittent hypoxia $(\mathrm{IH})$ and from sleep fragmentation. Overweight is observed in the majority of patients with OSA. The mechanisms of the association between OSA and obesity are still unclear. Excessive fat deposits may participate in OSA as a predisposing factor, as a consequence, or as both [4].

\footnotetext{
* Correspondence: cintiazfiori@gmail.com

${ }^{2}$ Graduate Program in Cardiology and Cardiovascular Sciences, Universidade Federal do Rio Grande do Sul (UFRGS), Cardiology Unit, Hospital de Clínicas de Porto Alegre (HCPA), (Ramiro Barcelos, 2350), Porto Alegre, (90035-903), Brazil

Full list of author information is available at the end of the article
}

Brown adipose tissue (BAT) function may be involved in obesity [5]. BAT produces heat through the action of uncoupling protein 1 (UCP1) [6]. During exposure to cold, UCP1 is physiologically regulated by catecholamines, thyroid hormones, and leptin $[7,8]$. BAT function can be stimulated by hypoxia [9]. Contrary to previous concepts [10], BAT is active in $2.5 \%$ [11] to $45 \%$ [12] of adult humans. BAT activity may need stimulation by cold to be detected $[13,14]$.

Exposure to IH is a model of OSA [15]. Previous reports demonstrated weight loss during exposure to constant hypoxia [16]. Our group reported [17] significant reduction in body weight and in brown adipose tissue wet weight (BATww) in rats subjected to IH for 21 days. OSA patients usually display weight gain [18]. Therefore, the weight loss seen in rodents may represent evidence that obesity is more a predisposing factor than a consequence of OSA. 
Because of the effects of hypoxia in several of the mechanisms controlling BAT function, such as, sympathetic function, leptin secretion, thyroid function, we hypothesized that $\mathrm{IH}$ can influence the total protein concentration (TPC) in BAT, a surrogate of BAT function. In the present study, we analyzed, in Balb/c mice, the effect of IH during 35 days on body weight, on BATww, and on TPC.

\section{Methods}

Two-month-old male Balb/c mice, from the FEPPS http://www.fepps.rs.gov.br/, Porto Alegre, Brazil, were separated in two groups: 12 mice submitted to 35 days of IH and 12 control mice, submitted to 35 days of sham intermittent hypoxia (SIH). Both groups were housed under temperatures ranging between $22.5-24.5^{\circ} \mathrm{C}$ and received ad libitum standard mice chow (Purina-Nutripal, Porto Alegre, RS, Brazil) and water. The protocol was approved by the institutional Ethics Committee and followed the "Guide for the Care and Use of Laboratory Animals" [19]. The mice were weighed at the baseline, 21 , and 35 days in a scale with precision of $0.01 \mathrm{~g}$ (Marte, model AS 5500C).

IH procedures were described in detail before. In brief, during five weeks, 7 days per week, 8 hours a day, from 9 a.m. to 5 p.m., in the lights on period, the animals were placed in the IH system (Figure 1). A mixture with 92\% nitrogen and $8 \% \mathrm{CO}_{2}$ was released in the hypoxia chamber, for 30 seconds. The gas mixture reduced the oxygen fraction from $21 \%$ to approximately $7 \pm 1 \%$ and increased the $\mathrm{CO}_{2}$ fraction to approximately $5 \pm 1 \%$. Subsequently, a fan insufflated room air into the chamber for 30 seconds, restoring the oxygen fraction to $21 \%$. Each hypoxia/normoxia cycle lasted for 60 seconds; in 8 hours, $480 \mathrm{IH}$ periods occurred, equivalent to an apnea index of 60 per hour. The SIH group remained in an adjacent cage and underwent the same fan activity as the IH group, but no gas mixture entered the cage in the hypoxia cycle. Gas insufflation and fan activity

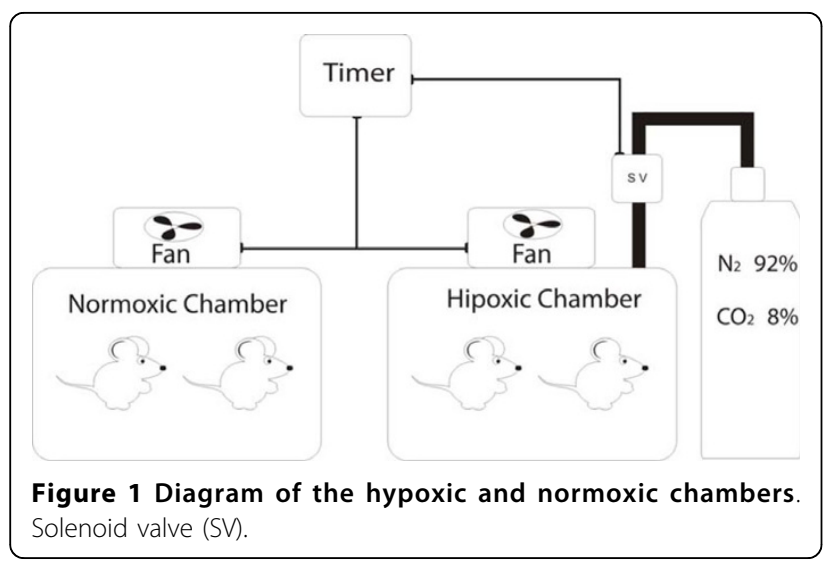

reduced temperature in the hypoxic cage by $0.2 \pm 0.3^{\circ} \mathrm{C}$, as compared to the normoxic cage that reduced $0.1 \pm$ $0.2^{\circ} \mathrm{C}$. Temperature was measured by fast-response thermocouple, averaged from three cage locations. Wind chill effect was minimized by deflectors under the fans.

\section{Extraction of brown adipose tissue}

After 35 days, the animals were anesthetized with ketamine $(100 \mathrm{mg} / \mathrm{kg})$ and xylazine $(10 \mathrm{mg} / \mathrm{kg})$ intraperitoneally. After deep anesthesia was confirmed, the interscapular BAT was extracted with fine-tipped straight surgical scissors and with anatomical tweezers. BAT was weighed while wet in a digital scale with precision of $0.0001 \mathrm{~g}$ (Bel Engineering, Italy) placed in microtubes, frozen in liquid nitrogen, and stored at $-80^{\circ} \mathrm{C}$ until the moment of analysis. After tissue removal, the animals were euthanized by exsanguination under anesthesia.

\section{Protein determination}

The BAT was homogenized and total protein concentration was determined by the Lowry method [20], using as standard a solution of bovine albumin $1 \mathrm{mg} / \mathrm{mL}$. The volumes of the solution used in the calculations were 50,100 and $150 \mu \mathrm{L}$, being represented in a concentration curve. An aliquot of the homogenized BAT $(20 \mu \mathrm{L})$ was mixed in $780 \mu \mathrm{L}$ of distilled water and $2.0 \mathrm{~mL}$ of reagent $\mathrm{C}$ which was prepared with $50 \mathrm{~mL}$ of $\mathrm{NaHCO} 3$ added with $0.5 \mathrm{~mL}$ of reagent $\mathrm{B} 1$ (CuSO $4 . \mathrm{H} 2 \mathrm{O} 1 \%)$ and $0.5 \mathrm{~mL}$ of reagent $\mathrm{B} 2$ (sodium tartrate and potassium $2 \%)$. After 10 minutes of the addition of reagent $C, 0.2$ $\mathrm{mL}$ of Folin-Ciocalteau reagent, diluted in a proportion of 1:3, was added in distilled water. After 30 minutes, a bluish color was observed and then TPC was measured in a spectrophotometer at $625 \mathrm{~nm}$. The TPC measurement from one mouse in IH group is unavailable because the microtube was lost.

Table 1 Mean and standard deviations of body weight in the two experimental groups

\begin{tabular}{lccc}
\hline & $\begin{array}{c}\text { Sham IH } \\
(\mathbf{n}=\mathbf{1 2})\end{array}$ & IH $(\mathbf{n}=\mathbf{1 2})$ & $\begin{array}{c}\mathbf{P} \text { between } \\
\text { groups }\end{array}$ \\
\hline $\begin{array}{l}\text { Body weight at day } \\
\mathbf{1}(\mathbf{g})\end{array}$ & $23.3 \pm 3.81$ & $24.4 \pm 3.33^{*}$ & 0.46 \\
\hline $\begin{array}{l}\text { Body weight at day } \\
\mathbf{2 1} \text { (g) }\end{array}$ & $25.8 \pm 3.70$ & $21.0 \pm 1.71^{* *}$ & $\mathbf{0 . 0 0 0 4}$ \\
\hline $\begin{array}{l}\text { Body weight at day } \\
\mathbf{3 5} \text { (g) }\end{array}$ & $24.1 \pm 2.96$ & $20.2 \pm 2.20$ & $\mathbf{0 . 0 0 1}$ \\
\hline $\mathbf{P}$ within groups & 0.23 & $\mathbf{0 . 0 0 0 4}$ & -
\end{tabular}

$\mathrm{IH}$ : Intermittent hypoxia. ${ }^{*} \mathrm{P}=0.0042$ comparing with body weight at day 21 and $\mathrm{P}=0.0004$ comparing with body weight at day 35 . ${ }^{* *} \mathrm{P}=0.307$ comparing with body weight at day 35 . Significant $P$ values are in bold type. Body weight compared by repeated measures ANOVA and by independent samples Student's t-test. 
Table 2 Means and standard deviations of data obtained at day 35 in both experimental groups

\begin{tabular}{lccc}
\hline & $\begin{array}{c}\text { Sham IH } \\
(\mathbf{n}=\mathbf{1 2})\end{array}$ & IH $(\mathbf{n}=\mathbf{1 2})$ & P Value \\
\hline $\begin{array}{l}\text { Body weight at day } \\
\mathbf{3 5}(\mathbf{g})\end{array}$ & $24.1 \pm 2.96$ & $20.2 \pm 2.2$ & $\mathbf{0 . 0 0 1}$ \\
\hline BATww $(\mathbf{g})$ & $0.0372 \pm 0.002$ & $0.0318 \pm 0.003$ & $\mathbf{0 . 0 0 0 0 3}$ \\
\hline TPC $(\boldsymbol{\mu} \mathbf{g} / \mathbf{1 0 0} \boldsymbol{\mu L})^{*}$ & $213.2 \pm 78.7$ & $204.4 \pm 44.3^{*}$ & 0.74 \\
\hline
\end{tabular}

IH: Intermittent hypoxia; BATww: Brown adipose tissue wet weight; TPC: Total protein concentration; ${ }^{*} n=11$. Significant $P$ values are in bold type.

\section{Statistical Analysis}

The results were expressed as mean value and standard deviation. We used SPSS v16 for all statistical analysis (SPSS Chicago, IL). To compare the studied means and variables between two groups we used the Student's t-test for independent samples between two groups, and for more than two groups was used analysis of variance (ANOVA). The significance level for alpha error was $\mathrm{p}<0.05$. Associations of body weight at day 35 with BATww and TPC levels were examined using Spearman's rank-order correlation coefficients due to the small sample size and the presence of outliers. To adjust correlations for confounders, we utilized linear regression to predict BATww using as regressors: exposure to $\mathrm{IH}$, body weight at day 35 , and TPC.

\section{Results}

Data obtained in IH and SIH groups are shown in Table 1 and Table 2. We observed no significant change in body weight in the SIH group whereas in the IH group a significant body weight loss was detected at day 21 and was further intensified at day 35 , but non-significantly ( $p=0.307)$. The correlation coefficients of TPC levels against body weight at day 35 and BATww were non-significant.

Significant relationship was observed between body weight at day 35 and BATww for the whole group. Splitting the IH and SIH groups, no significant correlation is seen (Figure 2).

The linear regression model, using BATww as the dependent variable is displayed in Table 3. Exposure to $\mathrm{IH}$ was the only variable that remained significant in the model. Partial correlations indicate that exposure to $\mathrm{IH}$ was the factor contributing most to the model, followed by TPC and body weight at day 35 . Adjusted $\mathrm{r}$ square denotes that $61 \%$ of the variance in BATww is explained by the three variables.

\section{Discussion}

The results of the present study indicate that 60 cycles of IH per hour, 8 hours a day, during 35 days cause reduction in body weight and in BATww, but no change in TPC of Balb/c mice. This confirms our previous findings in a rat model of OSA during 21 days [17]. The weight changes are negligible after 21 days.

Body weight at day 35 and BATww are positively correlated. In multivariate analysis, however, the correlation is explained only by exposure to $\mathrm{IH}$, suggesting that $\mathrm{IH}$ has direct effect on BATww and that body weight loss is less influent as cause of BATww reduction.

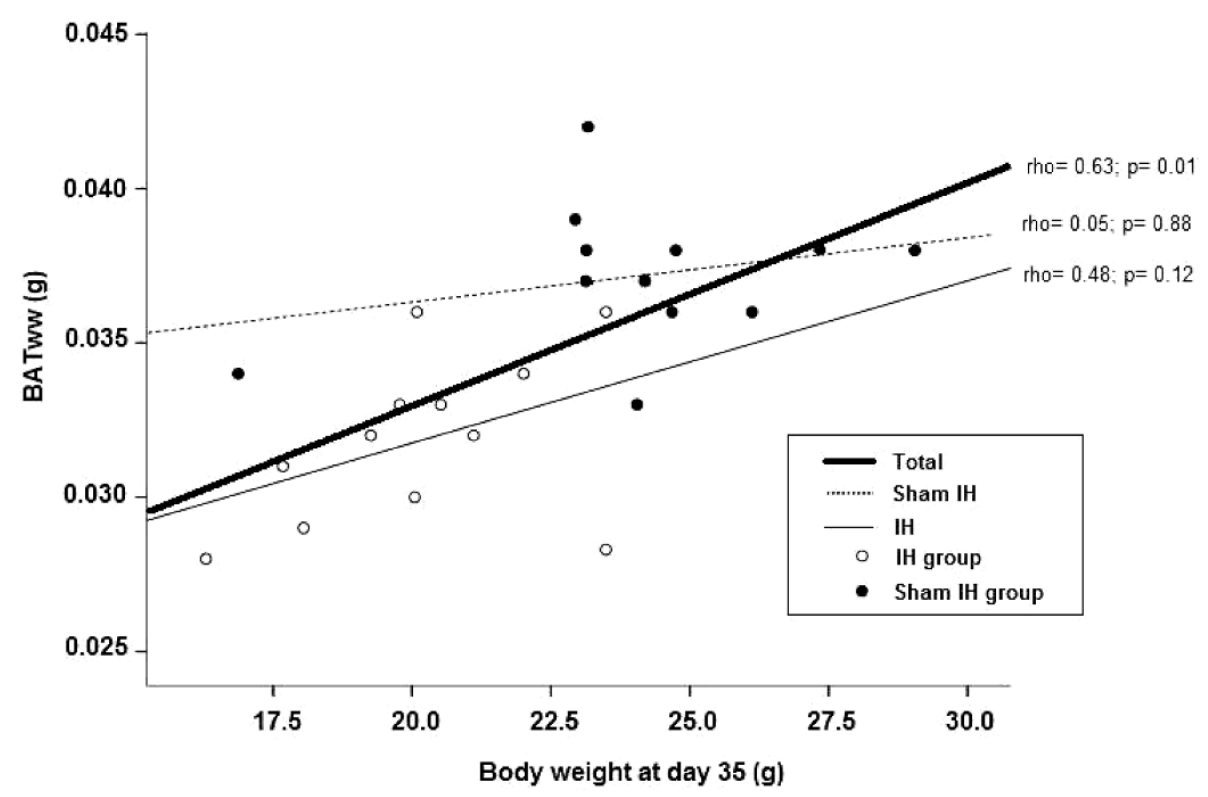

Figure 2 Scatterplot of brown adipose tissue wet weight by body weight at day 35 
Table 3 Results from linear regression model to predict brown adipose tissue wet weight

\begin{tabular}{|c|c|c|c|c|c|c|}
\hline & & Unstand & ed Coefficients & Standardized Coefficient & & \\
\hline Dependent variable & Regressors & B & Standard error & Beta & Partial $r$ & $P$ value \\
\hline \multicolumn{7}{|l|}{$\overline{\text { BATww (g) }}$} \\
\hline & Intercept & 0.027179 & 0.00648 & - & - & 0.0004 \\
\hline & $\| \mathrm{H}($ exposed, 1) & -0.00419 & 0.00151 & -0.57 & -0.54 & 0.012 \\
\hline & $\mathrm{TPC}(\mu \mathrm{g} / 100 \mu \mathrm{L})$ & 0.000016 & 0.00002 & 0.26 & 0.41 & 0.067 \\
\hline & Body weight at day $35(\mathrm{~g})$ & 0.000278 & 0.00027 & 0.23 & 0.25 & 0.2727 \\
\hline & Adjusted $R^{2}=0.61$ & & & & & \\
\hline
\end{tabular}

$\mathrm{IH}$ : Intermittent hypoxia; BATww: Brown adipose tissue wet weight; TPC: Total protein concentration. Significant P value is in bold type.

Our finding that weight loss plateaus at 21 days prompts future research comparing BATww at shorter durations of exposure to $\mathrm{IH}$, for instance, one or two weeks. The significant relationship observed between body weight at day 35 and BATww for the whole group could mean that the white and brown fat are simply parts of the total fat deposit which increase and decrease in tandem (Figure 2). The fact, however, that when splitting the $\mathrm{IH}$ and $\mathrm{SIH}$ groups, a much lower correlation is seen for the SIH group suggest that IH has a direct effect on BATww, supported by the multivariate analysis (Table 3).

BAT activation occurs at room temperatures between $4-16^{\circ} \mathrm{C}[9,13,21-23]$. In our study, temperature exhibited trivial differences between $\mathrm{IH}\left(22.9 \pm 2.5^{\circ} \mathrm{C}\right)$ and SIH cages $\left(23.2 \pm 2.1^{\circ} \mathrm{C}\right)$. It is, therefore, improbable that procedure-induced temperature changes could influence BAT behavior.

In conclusion, animals submitted to $\mathrm{IH}$ present weight loss and reduction of BATww. We were unable to demonstrate indirect effect of $\mathrm{IH}$ on thermogenic activity measuring protein concentration in BAT as surrogate of UCP1 function. Twenty-one days are sufficient to provoke weight loss in IH models. Understanding of the mechanisms of weight loss under IH requires further investigations.

\footnotetext{
Abbreviations

HI: Intermittent hypoxia; BAT: Brown adipose tissue; TPC: Total protein concentration; SIH: Sham intermittent hypoxia; BATww: Brown adipose tissue wet weight; OSA: Obstructive sleep apnea; UCP1: Uncoupling protein 1; SV: Solenoid valve.
}

\section{Acknowledgements}

Research was supported by FIPE - HCPA (Brazil); Miss Fiori is recipient of a student master scholarship from the Brazilian government agency CNPq. Fabiola S Meyer participated in the maintenance and veterinary care of the experimental model; Paulo R O Thomé participated in the engineering and maintenance of the $\mathrm{IH}$ system; Marta J G Cioato participated in the maintenance and administration of the $\mathrm{H}$ system.

\section{Author details}

${ }^{1}$ Cardiology Unit, Universidade Federal do Rio Grande do Sul, Brazil, Hospital de Clínicas de Porto Alegre (HCPA), (Ramiro Barcelos, 2350), Porto Alegre, (90035-903), Brazil. ${ }^{2}$ Graduate Program in Cardiology and Cardiovascular Sciences, Universidade Federal do Rio Grande do Sul (UFRGS), Cardiology
Unit, Hospital de Clínicas de Porto Alegre (HCPA), (Ramiro Barcelos, 2350), Porto Alegre, (90035-903), Brazil. ${ }^{3}$ Graduate Program in Medical Sciences, Universidade Federal do Rio Grande do Sul (UFRGS), (Ramiro Barcelos, 2400), Porto Alegre, (90035-903), Brazil. ${ }^{4}$ Graduation in Biomedicine, Universidade Federal de Ciências da Saúde de Porto Alegre (UFCSPA), (Sarmento Leite, 245), Porto Alegre, (90050-170), Brazil. ${ }^{5}$ Unit of Geriatrics, Hospital São Lucas da PUCRS, (Avenida Ipiranga, 6690), Porto Alegre, (90610-000), Brazil.

\section{Authors' contributions}

DM conceived the study, and participated in its design, coordination and in writing the manuscript; CZF in the design of the study, performed the dissection and weighing of the tissues and the statistical analysis; DB helped to draft the manuscript; RSK participated in the handling of animals; LJK helped to draft the manuscript; $A C$ helped in the statistical analysis; $A B$ helped in the statistical analysis. All authors read and approved the final manuscript.

\section{Competing interests}

The authors declare not having any personal or financial support or involvement with organizations with financial interest in the subject matter or any actual or potential conflict of interest.

Received: 27 April 2010 Accepted: 19 October 2010 Published: 19 October 2010

\section{References}

1. American Academy of Sleep Medicine Task Force: Sleep-related breathing disorders in adults: recommendations for syndrome definition and measurement techniques in clinical research. Sleep 1999, 22(5):667-89.

2. The International Classification of Sleep Disorders. In Diagnostic and Coding Manual. Edited by: Hauri PJ. Westchester, American Academy of Sleep Medicine; , 2 2005:.

3. Bradley TD, Brown IG, Grossman RF, Zamel N, Martinez D, Phillipson EA, Hoffstein V: Pharyngeal size in snorers, nonsnorers, and patients with obstructive sleep apnea. N Engl J Med 1986, 315(21):1327-31.

4. Shah N, Roux F: The relationship of obesity and obstructive sleep apnea. Clin Chest Med 2009, 30(3):455-65.

5. Cinti S: The role of brown adipose tissue in human obesity. Nutr Metab Cardiovasc Dis 2006, 16(8):569-74.

6. Cannon B, Nedergaard J: Brown adipose tissue: function and physiological significance. Physiol Rev 2004, 84(1):277-359.

7. Golozoubova V, Cannon B, Nedergaard J: UCP1 is essential for adaptive adrenergic nonshivering thermogenesis. Am J Physiol Endocrinol Metab 2006, 291(2):E350-E357

8. Ribeiro MO, Bianco SD, Kaneshige M, Schultz JJ, Cheng SY, Bianco AC, Brent GA: Expression of uncoupling protein 1 in mouse brown adipose tissue is thyroid hormone receptor-beta isoform specific and required for adaptive thermogenesis. Endocrinology 2010, 151(1):432-40.

9. Mortola JP, Merazzi D, Naso L: Blood flow to the brown adipose tissue of conscious young rabbits during hypoxia in cold and warm conditions. Pflugers Arch 1999, 437(2):255-60.

10. Nedergaard J, Bengtsson T, Cannon B: Unexpected evidence for active brown adipose tissue in adult humans. Am J Physiol Endocrinol Metab 2007, 293(2):E444-E52. 
11. Hany TF, Gharehpapagh E, Kamel EM, Buck A, Himms-Hagen J, von Schulthess GK: Brown adipose tissue: a factor to consider in symmetrical tracer uptake in the neck and upper chest region. Eur J Nucl Med Mol Imaging 2002, 29(10):1393-8.

12. Rousseau C, Bourbouloux E, Campion L, Fleury N, Bridji B, Chatal JF, Resche I, Campone M: Brown fat in breast cancer patients: analysis of serial (18)F-FDG PET/CT scans. Eur J Nucl Med Mol Imaging 2006, 33(7):785-91

13. Van Marken Lichtenbelt WD, Vanhommerig JW, Smulders NM, Drossaerts JM, Kemerink GJ, Bouvy ND, Schrauwen P, Teule GJ: Coldactivated brown adipose tissue in healthy men. N Engl J Med 2009, 360(18):1500-8.

14. Virtanen KA, Lidell ME, Orava J, Heglind M, Westergren R, Niemi T, Taittonen M, Laine J, Savisto NJ, Enerbäck S, Nuutila P: Functional brown adipose tissue in healthy adults. N Engl J Med 2009, 360(11):1518-25.

15. Fletcher EC: Invited review: Physiological consequences of intermittent hypoxia: systemic blood pressure. J Appl Physiol 2001, 90(4):1600-5.

16. Leal TL, Alippi RM, Vargas M, León-Velarde F, Bozzini CE: Body weight loss during acute hypoxia: effects of increased convective oxygen transport or previous acclimation. Acta Physiol Pharmacol Ther Latinoam 1995, 45(1):9-14.

17. Martinez D, Vasconcellos LF, de Oliveira PG, Konrad SP: Weight loss and brown adipose tissue reduction in rat model of sleep apnea. Lipids Health Dis 2008, 31(7):26.

18. Phillips BG, Kato M, Narkiewicz K, Choe I, Somers VK: Increases in leptin levels, sympathetic drive, and weight gain in obstructive sleep apnea. Am J Physiol Heart Circ Physiol 2000, 279(1):H234-7.

19. National Research Council: Guide for the care and Use of Laboratory Animals. Washington, D.C.: National Academy Press 1996.

20. Lowry OH, Rosebrough NJ, Farr AL, Randall RJ: Protein measurement with the Folin phenol reagent. J Biol Chem 1951, 193(1):265-725.

21. Morrison SF: Central pathways controlling brown adipose tissue thermogenesis. News Physio/ Sci 2004, , 19: 67-74.

22. Nikami H, Shimizu Y, Endoh D, Yano H, Saito M: Cold exposure increases glucose utilization and glucose transporter expression in brown adipose tissue. Biochem Biophys Res Commun 1992, 185(3):1078-82.

23. Suzuki D, Murata Y, Oda S: Changes in Ucp1, D2 (Dio2) and Glut4 (Slc2a4) mRNA expression in response to short-term cold exposure in the house musk shrew (Suncus murinus). Exp Anim 2007, 56(4):279-88.

doi:10.1186/1476-511X-9-121

Cite this article as: Martinez et al.: Brown adipose tissue: is it affected by intermittent hypoxia?. Lipids in Health and Disease 2010 9:121.

\section{Submit your next manuscript to BioMed Central and take full advantage of:}

- Convenient online submission

- Thorough peer review

- No space constraints or color figure charges

- Immediate publication on acceptance

- Inclusion in PubMed, CAS, Scopus and Google Scholar

- Research which is freely available for redistribution

Submit your manuscript at www.biomedcentral.com/submit
Biomed Central 